\title{
Current Problems in the Mental Health Field
}

\author{
Kilda Çela Gusha \\ Specialist of Public Health, Shkoder. Albania;
}

Irena Shala

Lecture at University of Shkodra. Albania;

Remila Kalo

University of Shkodra Luigj Gurakuqi.Albania

\begin{abstract}
Mental health problems are conditions that do not meet the criteria for disease but affect the normal quality and continuity of everyday life. They are the emotional and psychological difficulties of the individual, which occur as a result of circumstantial or persistent stresses or of a reflection of the emotions between the individual and the environment where he lives (WHO, 2005). Health is seen as "not just a lack of sickness or disability," but rather as "a complete physical, mental and social well-being." This definition significantly expands the concept of mental health, which should not be defined in a restrictive manner as the absence of mental disorders, but should be defined in a positive and comprehensive view (WHO, 1985). Ultimately, mental health is defined as "a state of well-being in which the individual realizes his or her own potential, is able to cope with daily life concerns, is productive and fruitfully in his work, and is capable of delivering his contribution to the community where he lives (WHO, 2001). Mental health problems are usually associated with important concerns in social, professional, or other important activities. In many cases, there appears to be a continuity between mental health problems and mental disorders, making the diagnosis even more complex (CDC, 2011). Policies and Legislative Frameworks. Law on MS - 1996. Implementation of LLL remains low as a consequence of inadequate infrastructure (health, social and legal). There is no national or local body to monitor human or patient rights in the institutions of the MS.Policy on the Development of Mental Health Services in Albania - March 2003. Action Plan for the Development of Mental Health Services in Albania - May 2005. Mental and emotional problems are a concern for many elderly people. Depression often occurs as a result of the death of a spouse or close friends. Even this kind of loss and even more important and more common is the loss of respect of others. With retirement an individual does not feel more useful to his family, to society, and even more to himself.
\end{abstract}

Keywords: current problems, mental, health, field

\section{Introduction}

\section{Definition of Mental Health?}

Mental health problems are conditions that do not meet the criteria for disease but affect the normal quality and continuity of everyday life. They are the emotional and psychological difficulties of the individual, which occur as a result of circumstantial or persistent stresses or of a reflection of the emotions between the individual and the environment where he lives (WHO, 2005).

Health is seen as "not just a lack of sickness or disability," but rather as "a complete physical, mental and social well-being." This definition significantly expands the concept of mental health, which should not be defined in a restrictive manner as the absence of mental disorders, but should be defined in a positive and comprehensive view (WHO, 1985).

Ultimately, mental health is defined as "a state of well-being in which the individual realizes his or her own potential, is able to cope with daily life concerns, is productive and fruitfully in his work, and is capable of delivering his contribution to the 
community where he lives "(WHO, 2001). Mental health problems are usually associated with important concerns in social, professional, or other important activities. In many cases, there appears to be a continuity between mental health problems and mental disorders, making the diagnosis even more complex (CDC, 2011).

Mental disorders also called mental illness $(\mathrm{NIH}, 2016)$ or psychiatric disorders are signs, complaints and conditions referred by the person and evaluated by the mental health professional. These disorders can cause suffering or a poor ability to a good functioning of life. They appear in an individual's cognitive abilities, emotional regulation or behavior that reflects, a dysfunction in psychological, biological processes or developmental processes based on mental function (Maisel, 2013).

Such characteristics may be persistent, laparotomy and remitting, or may occur as a single episode. Generally, they are characterized by a combination of thoughts, perceptions, emotions, behaviors, and abnormal relationships with others influenced by factors in the local context (Patel et.al, 2007).

These cases after assessed by the mental health professional, are classified and end up with the diagnosis of a disorder affecting the cognitive and emotional function of the individual. Many disorders have been described, with signs and symptoms that vary widely between specific disorders. Mental disorders may include mood disorders (depression), psychotic disorders (schizophrenia), etc. (WHO, 2015; WHO, 2016).

Everywhere in the world has effective strategies for preventing mental problems such as depression or other issues. There are effective treatments for these disorders and ways to alleviate the suffering caused by them. Access to healthcare and social services capable of addressing, supporting and managing these issues is the key to success.

The treatment gap of mental disorders and mental disorders continues to grow with a significant impact on health and social, human and economic rights in all countries of the world (Demyttenaere et al., 2004).

\section{The history of mental problems in the world}

References to mental problems or disorders in the early Egyptian, Indian, Greek, and Roman scriptures show that doctors and philosophers who visualized the problems of human behavior considered mental problems as a reflection of the gods' dissatisfaction or evidence that these people possessed demons. Only a few of these doctors and philosophers realized that individuals who exhibited mental problems should be treated humane and not expelled, condemned, or tried to release them from the evil spirit (Gibbons et al 2017, Daisy, 2013, Mervat, 1987 ).

However, some Greek writers who were dealing with the field of medicine, such as Hippocrates (who flourished around BC $400 \mathrm{BC}$ ) considered mental problems as diseases that were to be understood as a relationship of troubled physiology (Pilgrim , 2007; Hinshaw, 2007). He and his followers emphasized the natural causes of clinical observation and brain pathology.

Later, these Greek writers applied that method that was practiced in imperial Rome, where the description for treating mental illness included a peaceful environment and work, and the use of drugs such as "purgative heat". It is thought that for the majority of people with psychosis their families have been cared for, while for those thought to be dangerous to themselves or to others, they were kept locked at home by relatives or guardians (Gibson, 2017; Hinshaw , 2007).

After the French Revolution, Philippe Pinel was assigned to the Paris Mental Health Hospital. Under the supervision of Pinel was introduced a completely new approach to the care of mental patients. Chains and shackles were removed, prisons were replaced in sunny rooms as well as patients were also allowed to perform exercise at the hospital.

After the French Revolution, Philippe Pinel was assigned to the Paris Mental Health Hospital. Under the supervision of Pinel was presented a completely new approach to the care of mental patients. Chains and shackles were removed, prisons were replaced in sunny rooms as well as patients were also allowed to perform exercise at the hospital.

Among other reformers we mention British layman William Tuke, who founded in 1796 the York Retreat Center for Human Mental Health Care and Vincenzo Chiarugi, who published in 1788 a humanitarian regiment for his hospital in Florence. During the 16-17th centuries many terms became known for mental disorders and found their way into everyday use (Gibbons, 2016, Kroll \& Bachrach, 1982, Schoeneman, 1977, Wright, 1997, Crossley, 2006, Dalby, 1997, Stompe et al 2006, Bedlam, 2003, Walsh, 1907, Dalby, 1993). 
By the end of the 17th century and during the Enlightenment era, insanity was increasingly seen as an organic physical phenomenon, irrelevant to the soul or moral responsibility. Asylum care was often quite harsh and treated people as wildlife, but at the end of the 18th century a moral movement of treatment for these patients developed gradually. Clear descriptions of some syndromes may be rare before the 19 th century.

Industrialization and population growth led to a massive expansion of the number and size of asylum for people with mental health problems in every western country during the 19th century. Various classification schemes and diagnostic conditions have been developed by the various authorities and the term psychiatrist was created in 1808 , although medical supervisors were still known as alienists (Gibbons, 2017, Geoffrey, 2002, Crossley, 2006 Dalby, 1997, Stompe et. al, 2006).

\section{History of mental illness in our country}

Regarding the treatment and pursuit of mental health problems for our country in the earliest times are scarce. The underdevelopment and lack of education as a result of the Ottoman rule, influenced the weak economic and social development. Like other branches of the field of medicine and the field of psychiatry and problems that it addresses for a long time was underdeveloped.

Patients with mental health problems often kept them locked up or left free, wandered in the streets without any help or support. Albanian society under the feudal system considered the mentally ill (or otherwise psychic) people as individuals affected by the demons. These superstitions allowed the various people, especially those who practiced religion, to create a mystery about them as a healer in the eyes of the people. They by means of their actions or dresses managed to deceive the people that they were able to heal these individuals by removing shadows and jinns from the sick (Vehbiu, Polimeri \& Pikuli, 1985).

\section{Data on mental problems in America}

Based on surveys conducted by two Epidemiological Catchment Area (ECA) and subsequent National Comorbidity Survey (NCS), over 200-2003, nearly half of Americans (46.4\%) reported meeting criteria in one points of their life with mental health problems or a mental state of anxiety disorder.

Diagnostic and Statistical Manual of Mental Disorders (DSM-IV) 28.8\%, mood disorder 20.8\%, 24.8\% impulse disorder and substance use disorders $14.6 \%$. These disorders for half of respondents started from the age of 14 and for $3 / 4$ of them up to the age of 24 (Kessler et al., 2005). While other studies report that about a quarter $(26.2 \%)$ meet criteria for various disorders, anxiety disorders 18.1\%; 9.5\% humor disorders; emotional control disorders (negative and positive) $8.9 \%$, as well as substance abuse disorders $3.8 \%$. A significant minority (23\%) met the criteria for more than two disorders. $22.3 \%$ of cases are classified as serious, 37.3\% are moderate and 40.4\% are light (Kessler et al., 2005; NIMS, 2006).

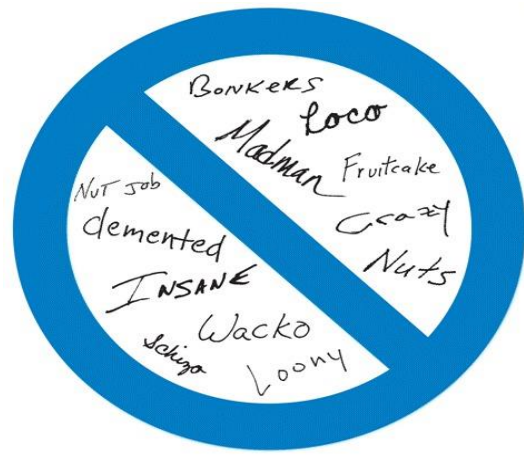

Figure

Words can hurt. Many derogatory words and phrases are used in relation to mental illness. However, these words maintain the stereotyped image and not the reality about mental illness. Try not to use these words, and encourage students not to use them. It is more appropriate to refer to "a person who has a mental illness" when speaking about someone 


\section{References}

[1] American Psychiatric Association. (2013). DSM-5 diagnostic classification. In: Diagnostic and Statistical Manual of Mental Disorders DSM-5. 5th ed. Arlington, Va.: http://www.psychiatryonline.org. 2015.

[2] Goldberg, D. \& Huxley, P. (1992). Common Mental Disorders: A Biosocial Model. London: Tavistock/Routledge.

[3] Health and Social Care Information Centre, (2007). Health Survey for England, 2005: Health of Older People. [online] Available at: http://www. hscic.gov.uk/pubs/hse05olderpeople [Accessed 14 Sep. 2015].

[4] http://www.who.int/mediacentre/factsheets/fs381/en/2016.

[5] Karel, M. J., Gatz, M., Smyer, M. (2012). Aging and mental health in the decade ahead: What psychologists need to know? American Psychologist. Vol. 67 (184-198).

[6] Royal Royal College of Psychiatrists (2014). Depression in Older Adults. [online] Available at: http://www.rcpsych.ac.uk/healthadvice/ problemsdisorders/depressioninolderadults.aspx [Accessed Aug. 2015].

[7] World Health Organization (2001). The World Health Report 2001. Mental Health: New Understanding, New Hope. Geneva: WHO.

[8] World Health Organization (WHO). The ICD-10 Classification of Mental and Behavioral Disorders: Clinical Descriptions and Diagnostic Guidelines. Geneva: World Health Organization; 1992. 